\title{
PRAZER E SOFRIMENTO NO TRABALHO: CONTRIBUIÇÕES À ORGANIZAÇÃO DO PROCESSO DE TRABALHO DA ENFERMAGEM
}

\author{
PLEASURE AND SUFFERING AT WORK: CONTRIBUTION TO NURSING LABOR \\ PROCESS ORGANIZATION
}

Wilson Danilo Lunardi Filho ${ }^{2}$

\begin{abstract}
RESUMO: O presente texto constitui-se numa síntese da Dissertação de Mestrado em Administração "Prazer e sofrimento no trabalho: contribuições à organização do processo de trabalho da enfermagem". Este trabalho de pesquisa teve como objeto de estudo a relação prazer, sofrimento e trabalho. Procurou estabelecer as implicações do trabalho em si, de sua organização e das condições oferecidas para seu desenvolvimento nos sentimentos de prazer e sofrimento dos trabalhadores da área de enfermagem.
\end{abstract}

UNITERMOS: Organização do trabalho - Prazer - Sofrimento.

\begin{abstract}
This paper is the synthesis of the author master program in administration thesis. It studied the pleasure, suffering and work relationship and searched to establish the implications of work itself, work organization and offered work conditions in the feelings of pleasure and suffering of nursing workers.
\end{abstract}

KEYWORDS: Work organization - Pleasure - Suffering.

\section{INTRODUÇÃO}

Esta pesquisa foi realizada com a finalidade de estabelecer as implicações do trabalho em si, de sua forma de organização e das condições oferecidas para seu desenvolvimento nos sentimentos de prazer e sofrimento no trabalho dos trabalhadores da enfermagem. Para tanto, foi realizada uma investigação, que teve na expressão do trabalhador seu ponto de destaque, fundamentando-se essencialmente, mas não exclusivamente, nas contribuições de Christophe Dejours (1992, 1993, 1994a, 1994b) e seus colaboradores (1993, 1994). Por sua vez, o acompanhamento do trabalho diário do pessoal de enfermagem, suas realizações, dificuldades, impossibilidades, momentos de descontração e, também, de sofrimento constituíram-se em elementos mobilizadores para o direcionamento do presente estudo.

\footnotetext{
Dissertação de Mestrado em Administração. Faculdade de Ciências Econômicas da Universidade Federal do Rio Grande do Sul. Tema Livre das Comunicaçōes coordenadas, $48^{\circ}$. Con2 gresso Brasileiro de Enfermagem - São Paulo, 06-11.10.96.

Enfermeiro. Docente do Curso de Enfermagem e Obstetrícia da Universidade do Rio Grande. Mestre em Administração. Doutorando em Filosofia da Enfermagem. Universidade Federal de Santa Catarina.
} 
Este trabalho é apresentado em cinco capítulos, sendo que, no Capítulo 1, são apresentados aspectos gerais sobre o trabalho, sua divisão e organização. São resgatados aqueles pontos considerados mais significativos para a compreensão do impacto da divisão e da organização do trabalho sobre o trabalhador, no que diz respeito à sua (des)qualificação, tornando-o cada vez mais sujeito a se tornar prescindivel e nas repercussões sobre sua saúde, tanto física quanto mental. São enfatizadas, principalmente, as contribuições de Christophe Dejours à análise da relação prazer, sofrimento e trabalho. No Capitulo 2, são abordados aspectos relativos ao papel social atual do trabalho, ressaltando seu caráter fundamental na construção da subjetividade e como fator de equilíbrio e desenvolvimento humanos. Como o foco de interesse é o trabalho da enfermagem hospitalar, são destacados os aspectos da emergência da burocratização das áreas hospitalar e de enfermagem, suas prováveis repercussões na qualidade do trabalho desenvolvido e possiveis implicações na gênese do sofrimento dos trabalhadores destas áreas. O Capítulo 3 apresenta a problemática geral de pesquisa e seus objetivos. São descritos aspectos relativos à metodologia de investigação e aos métodos de coleta e análise de dados. Apresenta também uma caracterização geral da instituição, onde os participantes desta pesquisa exerciam, à época, suas atividades profissionais. No capítulo 4, são apresentados a caracterização dos entrevistados, a partir dos dados obtidos por meio do roteiro de questões fechadas, e os resultados da análise temática do conteúdo das entrevistas. Na última parte deste trabalho, são retomados aspectos da literatura estudada que deram suporte teórico ao presente estudo. São tecidas considerações acerca dos resultados obtidos, cujos achados corroboram muitas das assertivas dos autores consultados, acrescentando-se a estas novas constatações que, espera-se, possam vir a se constituir em contribuição, ainda que pequena, aos estudos da relação prazer, sofrimento e trabalho.

\section{CONTRIBUIÇÕES DE CHRISTOPHE DEJOURS À ANÁLISE DA RELAÇÃO PRAZER, SOFRIMENTO E TRABALHO}

A seguir, pontuo, sinteticamente, aquelas contribuições que considero o eixo norteador teórico de construção da dissertação. Para tanto, inicio pela análise que Dejours faz do taylorismo, principalmente sobre suas repercussões na saúde do corpo.

Dejours entende que a organização científica do trabalho constituiu-se numa nova tecnologia de submissão e disciplinarização do corpo, geradora de exigências fisiológicas, até então desconhecidas, especialmente as exigências de tempo e ritmo de trabalho. Justifica tal assertiva afirmando que, para o operário-artesão pré-tayloriano, tudo se passava como se a atividade motora fosse regulada, modulada, repartida e equilibrada em função das suas aptidões e de seu cansaço, por meio da programação intelectual espontânea do trabalho. Em outras palavras, o corpo obedecia ao pensamento que, por sua vez, era controlado pelo aparelho psíquico, lugar do desejo e do prazer, da imaginação e 
dos afetos. Dessa forma, o corpo aparece como o principal ponto de impacto dos prejuizos provenientes do trabalho taylorizado, em decorrência das novas performances exigidas. Por sua vez, ao separar, radicalmente, o trabalho intelectual do trabalho manual, o taylorismo neutraliza a atividade mental dos trabalhadores. Desse modo, não é o aparelho psíquico que aparece como vítima do sistema, mas sobretudo o corpo dócil e disciplinado, entregue sem obstáculos à injunção da organização do trabalho e à direção hierarquizada do comando: corpo sem defesa, corpo explorado, corpo fragilizado pela privação de seu protetor natural que é o aparelho mental.

A organização do trabalho, para Dejours, é, de certa forma, a expressão da vontade de outro. O trabalhador, domesticado e forçado a agir conforme a vontade de outro, de certa forma, é despossuído de seu corpo físico e nervoso (desapropriado de sua competência). Ao ocupar, na organização, um cargo e ao desempenhar uma função, encontra à sua espera uma série de tarefas que deve cumprir. Encontra, também, os objetivos e os meios com os quais terá de trabalhar (nem sempre qualitativa e quantitativamente suficientes como se pôde constatar), ou seja, o seu trabalho já está determinado, restando-lhe, apenas, executá-lo. Portanto, a organização do trabalho é, primeiramente, a divisão do trabalho e sua repartição entre os trabalhadores, isto é, a divisão de homens recortando, assim, de uma só vez, tanto o conteúdo da tarefa quanto as relações humanas de trabalho. Fracionamento máximo e rigidez intangivel da organização científica do trabalho aparecem, então, como as características fundamentais do taylorismo, que engendra mais divisões entre os indivíduos do que pontos de união, confrontando os trabalhadores, um por um, individualmente e na solidão, às violências da produtividade. Por outro lado, ao mesmo tempo que isola o trabalhador dos outros pode colocá-lo em oposição aos demais. Ao não acompanhar as cadências, o operário que atrasa atrapalha os que o seguem na corrente de gestos produtivos. Tal é o paradoxo do sistema que dilui as diferenças, cria o anonimato, enquanto individualiza os homens frente ao sofrimento.

Portanto, a realidade dos riscos no trabalho taylorizado não é tanto devida às cadências em si, mas à violência que exerce no funcionamento mental, ao desapropriar o trabalhador de sua competência, a fim de centralizá-la em nivel de direção, tornando possivel, dessa forma, uma redivisão do trabalho e uma redefinição dos modos operatórios, em atenção aos desejos da direção, em detrimento da livre organização do trabalho, até então, privilégio do operárioartesão.

Por sua vez, uma organização do trabalho autoritária, rígida e imutável, impossibilitando seu rearranjo pelo trabalhador, ou seja, quando nenhuma adaptação do trabalho à personalidade é possível, mesmo embora este até nem seja muito dividido ou parcelado, conduz a um aumento da carga psíquica que não acha descarga no exercício do trabalho, resultando um sentimento de desprazer, fadiga e tensão. O sofrimento no trabalho, dessa forma, inicia quando existe bloqueio na relação homem-organização do trabalho, apesar da utilização máxima das faculdades intelectuais, psicoafetivas, de aprendizagem e de 
adaptação. No domínino da carga física, o perigo é o de um excessivo emprego de aptidões fisiológicas. Em relação à carga psíquica, o perigo principal reside no subemprego de aptidões psíquicas, fantásmicas ou psicomotoras, acarretando uma retenção da energia pulsional, o que constitui, precisamente, a carga psíquica do trabalho.

Quando o trabalho se opõe à livre atividade do aparelho psiquico, ele tornase perigoso, pois o bem-estar em termos de carga psíquica não advém só do funcionamento mas, ao contrário, de um livre funcionamento, dialeticamente articulado com o conteúdo da tarefa, expresso, por sua vez, na própria tarefa e revigorado por ela. O prazer resulta da descarga de energia psíquica que a tarefa autoriza, o que corresponde a uma diminuição da carga psíquica do trabalho. Segundo Dejours, a carga psíquica do trabalho constitui-se no regulador da carga global do trabalho. $O$ trabalho que permite a diminuição da carga psíquica é equilibrante. $O$ trabalho que se opõe a esta diminuição é fatigante.

A partir de seus estudos, Dejours demonstra que as pressões, que põem particularmente em causa o equilíbrio psíquico e a saúde mental, provêm da organização do trabalho, em contraposição aos constrangimentos perigosos para a saúde somática que se situam nas condições de trabalho, mais precisamente, nas condições físicas, químicas, biológicas e mecânicas, cujo principal alvo é o corpo.

No entanto, o trabalhar é um ato imprescindivel para as pessoas, mesmo que parcelar e especializado, pois refere-se à própria sobrevivência e condicionamento social do indivíduo. A atividade profissional, dessa forma, não é só um modo de ganhar a vida. É, também, uma forma de inserção social onde aspectos psíquicos e físicos estão fortemente implicados. $O$ trabalho pode ser um fator de deterioração, de envelhecimento e de doenças graves. Porém, pode constituir-se, também, em um fator de equilibrio e de desenvolvimento. $O$ trabalho, de fato, não é sempre patogênico. Ele tem, ao contrário, um poder estruturante, em face tanto da saúde mental como da saúde física.

Portanto, o trabalho também pode ser fonte de prazer e, mesmo, mediador de saúde. Conforme Dejours, em sua luta contra o sofrimento, às vezes, o sujeito elabora soluções originais que são favoráveis tanto à produção quanto à saúde. Tal forma de sofrimento foi por ele denominada de sofrimento criativo. Quando, ao contrário, nessa luta contra o sofrimento, o sujeito chega a soluções desfavoráveis tanto à produção quanto à saúde, tal forma de sofrimento caracteriza-se como sofrimento patogênico.

A transformação do sofrimento em criatividade exige uma organização do trabalho flexível, que permita o pleno emprego das aptidões psicomotoras, psicossensoriais e psíquicas, de modo a deixar maior liberdade ao trabalhador para rearranjar seu modo operatório e utilizar-se de gestos capazes de the proporcionar prazer, transformando um trabalho fatigante em um trabalho equilibrante. Portanto, o problema que se coloca para a administração seria, 
antes de tudo, propiciar condições aos trabalhadores para eles mesmos gerirem seu sofrimento, em proveito próprio e da produtividade.

\section{A QUESTÃO DE PESQUISA E OS OBJETIVOS}

De posse desse referencial teórico, formulei como questão norteadora de meu trabalho de dissertação, a seguinte pergunta:

"Quais os fatores que têm implicações na gênese do prazer e do sofrimento no trabalho, na opinião dos profissionais da área de enfermagem?"

Para direcionar o estudo foi estabelecido como objetivo geral, identificar fatores que, na percepção das categorias funcionais da enfermagem, "enfermeiro e auxiliar de enfermagem", têm implicações na gênese do prazer e do sofrimento no trabalho e, como objetivos especificos, foram estabelecidos: a) caracterizar os entrevistados das categorias enfermeiro e auxiliar de enfermagem que trabalhavam, à época, no hospital selecionado, em relação às seguintes variáveis: idade, sexo, estado civil, nível de escolaridade, turno de trabalho, tempo de serviço na área, tempo de serviço na instituição, faixa salarial, número de dependentes, local de trabalho e número atual de empregos; b) identificar convergências e divergências na percepção de prazer e sofrimento no trabalho, possivelmente decorrentes das variáveis acima especificadas.

O equacionamento desta questão, em atenção aos objetivos propostos, permitiu identificar os seguintes fatores: a) as características que configuram o perfil dos entrevistados das categorias enfermeiro e auxiliar de enfermagem da instituição estudada; b) a percepção dos entrevistados destas categorias funcionais a respeito de fatores que têm implicações na gênese do prazer e do sofrimento no trabalho.

\section{METODOLOGIA DA PESQUISA}

Em decorrência da natureza do objeto de estudo e pelas dificuldades que se apresentam em estabelecer os fatores implicados na gênese do prazer e do sofrimento no trabalho, uma vez que tanto o prazer como o sofrimento, em analogia à dor, não podem ser definidos de maneira satisfatória, salvo quando cada indivíduo os enuncia de modo introspectivo para si, optei por uma metologia de pesquisa cuja coleta de dados se deu por meio de entrevistas semi-estruturadas.

As entrevistas foram realizadas junto a profissionais da área de enfermagem, das categorias enfermeiro e auxiliar de enfermagem, entre 14 de outubro e 30 de dezembro de 1994; realizadas em local reservado, preferentemente distinto do ambiente de trabalho e em horário outro que não o dos turnos de trabalho, e gravadas, com a aquiescência dos entrevistados, para serem posteriormente transcritas. 
A transcrição deu-se, na íntegra e após cada entrevista, pelo próprio pesquisador, para garantir a máxima fidelidade, o sigilo e 0 anonimato necessários. Preferentemente, uma nova entrevista só era realizada após a total transcrição da entrevista anterior. As entrevistas tiveram uma duração média de 50 minutos, entre um mínimo de 30 e um máximo de 90 minutos. Durante a realização das entrevistas, foram apresentadas as seguintes questões:

\section{1 - Qual o significado do trabalho para você?}

\section{2 - Você tem prazer no trabalho? O que dá prazer no trabalho?}

\section{3 - Você tem sofrimento no trabalho? O que dá sofrimento no trabalho?}

A intervenção do entrevistador foi mínima, acontecendo somente quando da realização de nova pergunta ou para, esporadicamente, um redirecionamento ao assunto, quando considerado pertinente, durante a exposição de fatos ou minúcias de detalhamento que se afastassem dos objetivos principais do presente estudo. Ao final de cada entrevista, eram realizadas perguntas, com base no roteiro de questões fechadas, para a obtenção de dados julgados necessários à pesquisa e para caracterização dos sujeitos entrevistados.

\section{A CARACTERIZAÇÃO DOS ENTREVISTADOS}

Participaram da pesquisa dezoito profissionais de enfermagem que trabalhavam, à época, em diferentes setores ou unidades e em turnos distintos. A diversidade de tais características foi intencional, com vistas a obter uma visão mais abrangente e diferenciada, relacionadas a estes aspectos. A amostra foi acidental, envolvendo, entretanto, profissionais destas duas categorias distintas. Dos entrevistados, nove são enfermeiras (50\%) e nove são auxiliares de enfermagem $(50 \%)$, todos do sexo feminino (100\%). Em relação à faixa etária, as enfermeiras encontram-se entre as idades de 28 a 47 anos, numa média aproximada de 36 anos; os auxiliares de enfermagem encontram-se entre as idades de 25 a 50 anos, numa média de 38 anos. Quanto ao estado civil, a grande maioria (6 enfermeiras e 7 auxiliares de enfermagem, perfazendo $72,23 \%$ ) é casada ou com uma união estável. No tocante ao número de dependentes, quatro enfermeiras $(44,4 \%)$ têm um dependente e apenas uma enfermeira tem dois dependentes. As demais enfermeiras $(44,4 \%)$ não possuem dependentes. Já seis auxiliares de enfermagem $(66,6 \%)$ têm apenas um dependente. Dos restantes, três auxiliares de enfermagem têm um, dois e três dependentes, respectivamente. Em relação à escolaridade, cinco enfermeiras $(55,6 \%)$ realizaram, além da graduação, uma especialização ou a licenciatura plena em enfermagem e as restantes quatro enfermeiras $(44,4 \%)$ possuem somente a graduação. Seis auxiliares de enfermagem $(66,7 \%)$ ainda não completaram o $2^{\circ}$. Grau, dois auxiliares de enfermagem $(22,2 \%)$ têm o $2^{\circ}$. Grau 
completo e somente um auxiliar de enfermagem possui apenas $01^{\circ}$. Grau, condição legal mínima para o exercício desta categoria profissional. Quanto ao turno de trabalho, cinco enfermeiras e cinco auxiliares de enfermagem $(55,6 \%)$ são do turno da tarde, duas enfermeiras e dois auxiliares de enfermagem $(22,2 \%)$ são do turno da manhã e duas enfermeiras e dois auxiliares de enfermagem $(22,2 \%)$ são do turno da noite. Em relação ao tempo de serviço na área, situa-se entre 1 e 13 anos, numa média aproximada de 8 anos para as enfermeiras e entre 3 e 20 anos para os auxiliares de enfermagem, numa média aproximada de 10 anos. Quanto ao tempo de serviço na instituição, situa-se entre 1 e 8 anos, numa média de 5 anos para as enfermeiras, e entre 1 a 7 anos, numa média de 5 anos para os auxiliares de enfermagem. Em relação à área de atuação, estão representados os seguintes setores ou unidades: Ambulatório e Serviço de Pronto Atendimento, com um entrevistado; UTI Pediátrica e Neonatológica, com dois entrevistados; Unidade de Internação Pediátrica, com dois entrevistados; Maternidade e Centro Obstétrico, com três entrevistados; Unidade de Internação Cirúrgica, com três entrevistados e Unidade de Internação de Clínica Médica, com sete entrevistados. Quanto ao número de empregos, cinco enfermeiras $(55,6 \%)$ têm apenas um emprego e as demais quatro enfermeiras $(44,4 \%)$ têm dois empregos. Por sua vez, sete auxiliares de enfermagem $(77,8 \%)$ têm apenas um emprego e, dos restantes, um tem dois empregos e outro três. Em relação à faixa salarial, esta situa-se entre 3,5 a 4,5 salários-mínimos (à época da coleta dos dados, o salário-mínimo era de $\mathrm{R} \$$ 70,00 ) para as enfermeiras e entre 2,5 a 3,5 salários-mínimos para os auxiliares de enfermagem.

\section{O MÉTODO DE ANÁLISE E OS RESULTADOS}

Dentre o conjunto das técnicas de análise de conteúdo, a escolha recaiu sobre a análise temática das entrevistas, mediada por categorizações, cujo funcionamento se dá por operações de desmembramento do texto, em unidades, segundo reagrupamentos analógicos.

Para tanto, foi adotada a seqüência de passos da metodologia de análise de conteúdo apresentada por Moraes (1993), consistindo das seguintes etapas:

1- Preparação das informações: a) transcrição das entrevistas gravadas, na íntegra e imediatamente após sua realização; b) leitura flutuante para destacar e selecionar aspectos pertinentes e relevantes ao estudo.

2 - Unitarização ou transformação do conteúdo em unidades: a) separação em parágrafos, de acordo com o conteúdo temático; b) reelaboração das unidades de registro, por meio de uma síntese posterior de cada parágrafo, como recurso facilitador ao manuseio das informações, 
embora mantendo constante preocupação em conservar tanto o sentido original como as próprias palavras do entrevistado, relacionadas ao tema.

3 - Categorização ou classificação das unidades em categorias: esta etapa, com base na temática, se processou pelo agrupamento das unidades de registro, a partir do desmembramento das várias entrevistas.

4 - Descrição: esta etapa constitui-se de operações por categorias iniciais, a partir da descrição de suas principais idéias.

5 - Interpretação: esta etapa constitui-se da elaboração das categorias intermediárias mais abrangentes, a partir das informações das categorias iniciais e, finalmente, da elaboração das categorias finais, na busca de uma síntese mais globalizadora e do alcance de níveis de interpretação e compreensão mais aprofundados.

Os resultados são apresentados em três conjuntos de categorias, nos quais as informações coletadas foram classificadas como:

CATEGORIAS INICIAIS - Apresentam as informações em maior nivel de detalhamento, com a utilização intensiva das próprias manifestações dos entrevistados. São vinte e nove as categorias iniciais, apresentadas sem uma ordenação ou seqüenciação dentro de qualquer critério. Estas categorias foram definidas, a partir do exame dos materiais, não tenho havido qualquer esforço de pré-definí-las.

CATEGORIAS INTERMEDIÁRIAS - São oito categorias intermediárias resultantes de uma reclassificação das informações, em que se reagrupam as categorias iniciais, objetivando um menor número de categorias, de caráter mais amplo e abrangente.

CATEGORIAS FINAIS - As três categorias finais originaram-se do reagrupamento das categorias intermediárias, resultando numa síntese globalizadora das percepções dos entrevistados acerca da relação prazer, sofrimento e trabalho, destacando fatores que, na percepção dos entrevistados, têm implicações na gênese do prazer e do sofrimento no trabalho.

\section{APRESENTANDO AS CATEGORIAS FINAIS}

Esta pesquisa, que tem por objeto a relação prazer, sofrimento e trabalho e por objetivo geral a identificação da percepção dos trabalhadores da área de enfermagem, acerca dos fatores envolvidos na gênese do prazer e sofrimento no trabalho, buscava, desde o seu início, as relações desta gênese com o trabalho em si, sua organização e as condições oferecidas para o seu desenvolvimento. 
Seguindo a metodologia de análise proposta, foi possível a realização de análises que levaram a descrições objetivas, sistemáticas e qualitativas dos depoimentos dos entrevistados, auxiliando a reinterpretar seu conteúdo e a atingir uma compreensão aprofundada de seus significados, bem como 0 conhecimento de aspectos e fenômenos da vida social, de outro modo inacessiveis.

\section{A CATEGORIA FINAL "O TRABALHO EM SI"}

O trabalho desponta como algo que complementa e dá sentido à vida, constituindo-se numa das coisas mais importantes. Seu significado transcende o simples atendimento de necessidades de ordem econômica ou emocional. Uma das grandes motivações para o trabalho na área da enfermagem é a necessidade de ajudar e de sentir-se útil. A perspectiva de estar fazendo alguma coisa de utilidade para ajudar alguém confere um prazer imenso. Numa visão idealizada, ressaltam o trabalho da enfermagem como sublime, grandioso e nobre, no qual o amor e a dedicação auxiliam na superação dos problemas e na realização de um trabalho recompensador e prazeroso.

Apesar de ser considerado um trabalho desgastante e das características de ser um trabalho que, na maioria das vezes, se desenvolve frente às situações críticas pelas quais passa o ser humano, como a doença, o sofrimento e a morte, há um gosto especial pelo trabalho que reside, principalmente, na execução de atividades assistenciais: ajudar as pessoas doentes, apoiar e promover seu bem-estar geral, acompanhar sua recuperação e alta e presenciar a felicidade tanto de pacientes como de seus familiares.

O trabalho, sob esta ótica, apresenta-se como mediador de realização pessoal e profissional, em decorrência da possibilidade de serem executados procedimentos e cuidados diretos ao paciente, ou seja, poder realizar o trabalho e poder contemplar seus resultados. A atuação exitosa em situações mais críticas, como a recuperação de um paciente mais grave, e, principalmente, o sucesso nas manobras de ressuscitação conduzem ao pleno sentimento de realização e constitui-se numa forma de prazer extremo.

A valorização do trabalho da enfermagem, traduzida por demonstrações de gratidão, comentários positivos, acerca do trabalho realizado, e o reconhecimento geral geram sentimentos de profundo prazer, muito embora, na maioria das vezes, o reconhecimento pelo trabalho e o prazer que confere tem se restringido, apenas, ao paciente, que sempre dá um retorno, por meio de seus gestos, atitudes ou palavras. Por outro lado, o sentimento do dever cumprido, após a realização de tudo o que tinha de ser feito e apesar de um dia de excessivo e cansativo trabalho, também constitui-se em gênese de prazer no trabalho.

A incerteza quanto à possibilidade de realizar o excessivo número de tarefas que lhes são impostas, diariamente, a impossibilidade de realizar o trabalho do modo concebido como o correto e, não raro, a impossibilidade total de agir são situações percebidas como causadoras de grande sofrimento no trabalho. A impotência frente a essas impossibilidades e incertezas conduz a sentimentos de culpa e a atitudes de excessivo zelo, ao se sentirem muito responsáveis, motivados pelo medo de que algo ocorra e que possa ser atribuído à negligência. Portanto, sentimentos de impotência, culpa e medo emergem como 
tributários do sofrimento no trabalho, ao resultarem, como produto, em um trabalho com uma qualidade que não corresponde ao volume do trabalho realizado.

A auto-imposição de uma gama muito diversificada de obrigações e deveres bem como as expectativas médicas e da administração são causa de intenso sofrimento. Por sua vez, as atividades administrativas e burocráticas não são apreciadas pelas enfermeiras, por serem percebidas como impedimento ao contato direto, o que as afasta do cuidado direto, privando-as de desfrutar do prazer que proporcionam.

Críticas depreciativas ao resultado do trabalho da enfermagem, ao não serem consideradas as condições nas quais o trabalho se realiza, são percebidas como imputação de culpa pelo insucesso das ações. Ao serem internalizadas induzem a perceberem-se como realmente culpados, o que origina muito sofrimento, mal-estar e uma sensação de fracasso profissional. Tais atitudes e comentários depreciativos servem de desestímulo, desencadeando sentimentos de desânimo, desilusão, cansaço e desgosto, denotando a falta de reconhecimento pelo trabalho realizado, privando-os, assim, de grande parte do prazer que o trabalho em si proporciona.

Resignação e frustração manifestam-se ante a impossibilidade de concorrer para o alívio do sofrimento ou evitar a morte de um paciente. Defrontar-se, direta e diariamente, com a morte coloca à mostra todo o despreparo em lidar com tal tipo de situação, porém, para as enfermeiras, um sofrimento muito maior do que ter de lidar com a morte é o ato de ter de comunicá-la aos familiares. Já para os auxiliares de enfermagem, o preparo do corpo após a morte, uma das situações pertinentes ao seu trabalho e considerada uma das piores e horriveis coisas, é percebida como muito mais terrível, quando se trata de criança e, especialmente, de natimorto.

A noção de que demonstrar sofrimento é mostrar uma fraqueza incompatível com os atos de consolar e ajudar, conduzem a situações angustiantes e muito sofridas, ao simularem fortaleza, em detrimento do fluir natural da emotividade. Justificam sua permanência, num trabalho tão desgastante e apesar do sofrimento que contém, pela possibilidade de poder fazer alguma coisa que conforte o paciente, mesmo não vencendo a doença e impedindo a morte. Consideram que o trabalho recompensa, pois, contraditoriamente, o trabalho da enfermagem em si origina muito prazer.

\section{A CATEGORIA FINAL "A ORGANIZAÇÃO DO TRABALHO"}

Em decorrência de sua complexidade, o trabalho hospitalar apresenta uma dimensão coletiva, ao ser realizado por uma equipe de trabalhadores, com formações e graus de qualificação diversificados, que evidenciam a necessidade do trabalho conjunto para sua concretização. Portanto, o êxito desse trabalho depende de cada um e seu resultado só será satisfatório mediante o desenvolvimento de um bom trabalho individual. Mostram-se conscientes da necessidade e importância do trabalho que realizam para o sucesso e o alcance 
dos objetivos assistenciais e, conseqüentemente, organizacionais. Acreditam que um clima de harmonia, compreensão e respeito e o conseqüente relacionamento amistoso e cordial, quando existente, favorece o compartilhamento de experiências, vivências e conhecimentos, bem como oportuniza condições do livre exercício de expressão para opinar e sugerir, acerca de questões assistenciais. Estas, quando acatadas ou levadas em consideração, são percebidas como situações que conduzem a um trabalho melhor e mais prazeroso. Por sua vez, a confraternização e a intimidade e a conseqüente informalidade nas relações pessoais e profissionais são percebidas como situações que favorecem o desenvolvimento de um trabalho de equipe solidário, desse modo, mais tranqüilo e prazeroso.

Manterem-se constante e continuamente ocupados e preocupados, principalmente as enfermeiras, em encontrar soluções para os problemas, mais especificamente traduzido na contínua busca de condições materiais para viabilizar o trabalho, é uma característica percebida como um defeito da profissão, ao se afastarem das funções que consideram inerentes ao próprio trabalho e por exercerem outras que, pela lógica, seriam de competência de outros profissionais ou serviços. A auto-imposição de uma série de obrigações em relação ao paciente, aos seus direitos e ao seu estado e não vislumbrar tal nível de exigência nos demais profissionais de outros serviços, além de não obter a resposta esperada, durante tentativas de compartilhar problemas e dificuldades, geram sentimentos de intenso sofrimento no trabalho.

Além da falta de colaboração na organização e manutenção do trabalho e do ambiente, a atuação médica, ao não observar as normas de funcionamento do serviço, contribui para sua desorganização, constituindo-se, muitas vezes, em empecilho à atuação da enfermagem. Portanto, a aparente inexistência de normas de conduta médica e a conseqüente desorganização de seu trabalho podem tornar-se um impeditivo a mais à realização de um trabalho completo, tornando muito difícil o trabalho coletivo, portanto, tributário do sofrimento no trabalho para os trabalhadores da enfermagem.

A normatização do trabalho é percebida como necessária para realizar o trabalho, desde que normas positivas e factíveis sejam estabelecidas. Porém, a postura autocrática da administração não tem possibilitado a participação do conjunto dos trabalhadores nas deliberações, conduzindo ao estabelecimento freqüente de normas ou determinações, geralmente, de caráter proibitivo, cerceando a autonomia e impondo limites e impossibilidades, sem discussão e sem uma prévia avaliação das reais possibilidades do grupo para cumpri-las. Estas são seguidas, na medida do possível e, geralmente, tornadas sem efeito, quando absurdas ou inviáveis, após algum tempo, porém nunca sem antes terem gerado muito desgaste e sofrimento no trabalho. Por outro lado, algumas vezes, há a ocorrência de burla às normas pela própria administração e, contraditoriamente, punições ao seu cumprimento. 
A não contratação de substitutos implica aumento das exigências fisicas e mentais, ao impor um ritmo acelerado e intenso ao trabalho, como solução à escassez de recursos humanos. A inexistência de uma política de provimento de recursos materiais não permite à equipe de enfermagem destinar seu tempo e atenção apenas à assistência, ao ter que sair à cata de condições para realizar o trabalho. Estas (in)decisões da administração também contribuem com grande parcela do sofrimento físico e mental no trabalho. Por outro lado, as prioridades destinam-se à aquisição de aparelhos e instrumentos para maior precisão diagnóstica, em detrimento de maior proteção, facilidade e segurança no tratamento, acarretando a carência de materiais de necessidade óbvia, em detrimento da saúde e proteção, tanto dos pacientes como dos próprios funcionários.

Poder reclamar a mais de um superior hierárquico e nenhum deles resolver, não saber que atitude tomar diante de alguns posicionamentos da direção, ante às dificuldades enfrentadas, diuturnamente, conduzem a sentimentos de grande impotência. Portanto, a falta de eco aos apelos e o descaso para com os problemas sentidos, o trabalho tendo que ser realizado, mesmo sem condições ou dispondo de alguma condição, somente após muita insistência, geram sentimentos de indignação.

A postura autocrática e ameaçadora da coordenação, percebida como uma afronta à dignidade e à integridade moral dos subalternos, gera sentimentos hostis e vontade de praticar atos concretos de violência contra quem representa o poder. A impotência e o medo de atitudes punitivas e a necessidade de se manter no emprego abafam qualquer esboço de resistência explícita, conduzindo a intenso sofrimento, traduzido em tristeza, mágoa e arraso. O medo de retaliações e represálias e, principalmente, de demissão emerge como um dos maiores motivos de sofrimento no trabalho. Desse modo, percebem-se como um grupo muito sofrido e desgastado, devido ao descrédito e falta de reconhecimento, e sujeito a um processo de castração que inviabiliza qualquer tentativa de mudança e inovação e que impõe limites, principalmente à atuação do enfermeiro, dentro de uma hierarquia onde há uma chefia para a qual não pode ser verbalizado o que se pensa ou o que se quer ou necessita para realizar o trabalho.

Mágoa, tristeza, humilhação e aborrecimento são formas de sofrimento que dizem respeito, também, às transferências de setor ou de turno de trabalho, sem consulta prévia, que são acatadas pelo medo de demissão. A inexistência de reuniões periódicas é percebida como sonegação do direito de expressão. Ocorrem esporadicamente e apenas na vigência de algum problema crítico, com predominância de reclamações e criticas a posturas e condutas do trabalhador, em detrimento da avaliação do resultado do trabalho e das condições para sua realização. Quando ocorrem, geralmente se dão num clima de extremo autoritarismo e desrespeito aos sentimentos dos subalternos. Emergem, dai, sentimentos hostis e de profunda mágoa, conduzindo à percepção de intenso sofrimento. 
Problemas decorrentes da inexperiência médica, associadas a atitudes de arrogância, auto-suficiência, preconceitos e onipotência; a preocupação e empenho constantes com a manutenção das condições necessárias, principalmente materiais e, especialmente, em situações emergenciais, para que, no caso de insucesso, este possa ser compartilhado, também, pela equipe médica; manter-se sempre ocupado, na constante busca de atividades para ocupar um possivel tempo ocioso e a preocupação de que sejam criados novos serviços, apesar da precariedade das condições atuais, conduzindo a novas e maiores exigências constituem-se em fatores diretamente implicados na gênese do sofrimento no trabalho.

Por outro lado, as influências do trabalho não se restringem, apenas, ao âmbito do trabalho. Este repercute nas necessidades e na vida pessoal e privada dos trabalhadores da área de enfermagem. O horário noturno, além de extremamente desgastante, gera transtornos fisiológicos (alteração de hábitos de sono e alimentação, além de interferir na vida familiar e de relacionamento social, ao ser em noites alternadas, associado à necessidade de realizar o trabalho doméstico e, não raro, a outro emprego). Os plantões de doze horas, aos finais de semana e feriados, são percebidos como um duplo sofrimento: um sofrimento por antecipação, muito maior, nos dias anteriores ao próprio plantão e, menor, em sua realização. $O$ trabalho aos domingos e feriados impõe restrições à vida familiar e social, cuja organização se dá em função dos horários de trabalho, bem como as justificativas para não se fazerem presentes aos diversos eventos, também são do âmbito do trabalho. Além disso, um salário percebido como extremamente pouco e injusto, pelo tipo de atividade e responsabilidade que têm, que apenas complementa a renda, impõe restrições à vida pessoal, ao não garantir condições decentes de sobrevivência, constituindose em fator tributário do sofrimento no trabalho.

\section{A CATEGORIA FINAL "AS CONDIÇÕES DE TRABALHO"}

O fato do hospital universitário caracterizar-se como um órgão formador de recursos humanos para a área da saúde, onde há uma contínua possibilidade de atender às necessidades de aprendizagem e aperfeiçoamento, é visto como potencialmente capaz de proporcionar prazer. Outros aspectos apontados como tributários do prazer no trabalho dizem respeito à disponibilidade de recursos humanos, materiais e técnicos para sua realização e de proteção ao trabalhador, tendo em vista a natureza e demais características desse mesmo trabalho. Por sua vez, as formas diferenciadas de tratamento às necessidades de cada setor influenciam, decisivamente, na percepção do prazer ou sofrimento no trabalho.

A escassez dos meios materiais emerge como um dos maiores sofrimentos no trabalho, senão o maior, para a equipe de enfermagem, especialmente para as enfermeiras, ao thes serem imputados julgamentos desabonadores, ao não proverem tais meios de trabalho aos demais. As carências de material básico e especializado e de proteção individual conduzem à necessidade de sua 
constante busca, implicando a perda de um tempo que poderia ser destinado à assistência. Apesar do desejo de querer ajudar e de querer fazer, emergem sentimentos hostis, como a raiva e irritação, e o cansaço que decorrem da frenética busca de condições para realizar o trabalho. Além disso, pelos atritos que ocasiona, interfere no relacionamento interpessoal. Quando, finalmente, são reunidas tais condições já houve grande perda da motivação. Ao ser suplantada a vontade de realizar a tarefa, o trabalho acaba sendo realizado por obrigação, conduzindo a uma sensação de desprazer com o trabalho.

Muitas vezes o trabalho só pode ser realizado na base do improviso. A impossibilidade de, até, adaptar ou improvisar, pela total falta de material é percebida, ao desencadear sentimentos de pânico, raiva, angústia e preocupação, como um desgaste físico e mental extremo, é considerada a pior parte do trabalho e origem de muito sofrimento. Por outro lado, o material para proteção individual, na maioria das vezes, insuficiente ou inadequado a suas funções protetoras, conduz a sentimentos de medo e muito sofrimento, pelo maior risco de contaminação que a inadequação ou inexistência de tais condições origina, especialmente ao terem que prestar cuidados a pacientes aidéticos. A falta de treinamento específico para trabalhar junto a este tipo de paciente, bem como a proibição expressa de solicitação do material de proteção ao almoxarifado, quando o mesmo não está disponivel no Centro de Material e Esterilização, contribui para intensificar tais sentimentos. Portanto, a negligência da instituição hospitalar, manifestada pela aparente falta de preocupação com as condições de trabalho a que estão sujeitos os trabalhadores da enfermagem, associada à desconsideração, tanto médica como da própria direção, às suas solicitações para a suspensão temporária ou mesmo apenas a redução da internação de pacientes (principalmente, aidéticos), tendo em vista a carência de condições materiais, tanto para poder assistir como para poder se proteger no trabalho, são apontadas como geradora de grande sofrimento no trabalho.

Desse modo, o excesso de atividades, decorrentes da insuficiência de pessoal e sua associação à falta de material, inviabiliza a realização de muitas tarefas, tornando, além de angustiante, praticamente impossivel a realização de um trabalho qualificado. Por outro lado, os médicos parecem não compartilhar estas dificuldades e impossibilidades. Apesar da falta dos meios interferir na realização do trabalho, tal fato não impede que haja cobrança, principalmente em situações críticas, podendo conduzir a julgamentos desabonadores acerca da competência técnica dos membros da equipe de enfermagem.

A incerteza quanto à continuidade de um tratamento que está obtendo bons resultados também aparece como tributário do sofrimento no trabalho da enfermagem. A falta de recurso humanos e materiais constituem-se num dos grandes fatores de sofrimento no trabalho, principalmente por representarem uma realidade incompativel com a imagem de um hospital universitário, cuja realidade vivenciada gera muita angústia. 


\section{CONSIDERAÇÕES FINAIS}

Com base na análise dos depoimentos, acredita-se que se possa afirmar que tudo aquilo que dificulta ou inviabiliza o atendimento das necessidades que os trabalhadores da enfermagem possuem de ajudar e de sentir-se útil implica sofrimento no trabalho. Tudo aquilo que facilita ou viabiliza o atendimento de tais necessidades constitui-se em gênese do prazer no trabalho. $O$ estudo possibilitou o conhecimento tanto da existência do prazer como do sofrimento no trabalho, suas localizações e o que os motivam.

O trabalho em si, apesar do sofrimento que contém, possibilita também vivenciar um prazer real, concreto. Grande parte do sofrimento reside na organização do trabalho e, especialmente, nas condições de trabalho, de forma real, dramática e quase absoluta. Porém, o prazer nestas manifesta-se, quase sempre, condicionada a algum fator, na maioria das vezes, inexistente, portanto, numa possibilidade futura, como uma expectativa de prazer. A precariedade das condições para a realização do trabalho, ao despontar como um dos grandes impeditivos ao prazer no trabalho e constituindo-se num dos maiores fatores tributários do sofrimento no trabalho dos trabalhadores da área de enfermagem, parece suplantar ou relegar a um plano secundário até mesmo os sofrimentos decorrentes de sua forma de organização.

Apesar dos sofrimentos decorrentes da organização do trabalho da enfermagem, as condições para realizar o trabalho, muitas vezes, impedem a concretização das tarefas assistenciais. Tal impedimento implica, possivelmente, sofrimento a alguém que precisa de ajuda e de cuidados. Este sofrimento alheio parece ser menos tolerado pelos trabalhadores da enfermagem do que os próprios sofrimentos decorrentes da forma de organização do trabalho a que estão submetidos. Portanto, originam-se, dai, situações anti-sublimatórias, conduzindo os trabalhadores da área de enfermagem à percepção de sentimentos tributários do sofrimento no trabalho, constituindo-se, dessa forma, em impedimentos ao prazer no trabalho. As reflexões dai derivadas demandam maiores estudos, provavelmente prestando-se a futuras pesquisas que, certamente, trarão grandes contribuições ao estudo da relação prazer, sofrimento e trabalho. 


\section{REFERÊNCIAS BIBLIOGRÁFICAS}

1. DEJOURS, C. A loucura do trabalho. 5. ed. São Paulo: Cortez-Oboré, 1992.

2. U Uma nova visão do sofrimento humano nas organizações. In: CHANLAT, J.F. (Org.). O indivíduo na organização: dimensões esquecidas. 2. ed. São Paulo: Atlas, 1993. v. I.

3. A carga psíquica do trabalho. In: DEJOURS, C., ABDOUCHELI, E. \& JAYET, C. Psicodinâmica do trabalho. São Paulo: Atlas, 1994a.

4. Trabalho e saúde mental: da pesquisa à ação. In: DEJOURS, C., ABDOUCHELI, E. \& JAYET,C. Psicodinâmica do trabalho. São Paulo: Atlas, 1994b.

5. DEJOURS, C., DESSORS, D. \& DESRIAUX, F. Por um trabalho, fator de equilíbrio. RAE, São Paulo, v. 33, n. 3, p. 98-104, mai./jun. 1993.

6. DEJOURS, C. \& ABDOUCHELI, E. Desejo ou motivação? a interrogação psicanalitica sobre o trabalho. In: DEJOURS, C., ABDOUCHELI, E. \& JAYET, C. Psicodinâmica do trabalho. São Paulo: Atlas, 1994.

7. LUNARDI FILHO, W. D. Prazer e sofrimento no trabalho: contribuições à organização do processo de trabalho da enfermagem. Porto Alegre, 1995, 288 p. Dissertação (Mestrado). Faculdade de Ciências Econômicas, Universidade Federal do Rio Grande do Sul, 1995.

8. MORAES, R. Análise de conteúdo. Porto Alegre: PUCRS, 1993. (mimeo). 